\title{
Predictors of reading skills at the first and second grade : The role of orthography
}

\section{Holopainen, Leena}

2020

Holopainen , L , Koch , A , Hakkarainen , A \& Kofler , D 2020 , ' Predictors of reading skills at the first and second grade: The role of orthography ', Reading Psychology, vol. 41 , no. 5 , pp. 461-484 . https://doi.org/10.1080/02702711.2020.1768988

http://hdl.handle.net/10138/336716

https://doi.org/10.1080/02702711.2020.1768988

unspecified

acceptedVersion

Downloaded from Helda, University of Helsinki institutional repository.

This is an electronic reprint of the original article.

This reprint may differ from the original in pagination and typographic detail.

Please cite the original version. 
Predictors of Reading Skills at the First and Second Grade: The Role of Orthography

Leena Holopainen,

University of Eastern Finland, School of Educational Sciences and Psychology, Finland

Arno Koch,

Justus Liebig University, Institute for Special Education, Germany

Airi Hakkarainen,

University of Helsinki, Open University, Finland

and

Doris Kofler

Free University of Brixen, Faculty of Education, Italy

Correspondence concerning this article should be addressed to Leena Holopainen

University of Eastern Finland

School of Educational Sciences and Psychology

PO Box 111, FI-80101 Joensuu, Finland

leena.holopainen@uef.fi

Phone: +358504072249 


\begin{abstract}
We investigated the predictive power of cognitive skills and background variables of 769 first and second grade children learning to read two orthographically different languages Finnish and German in three countries Finland, Germany and Italy. Main results from stepwise regression models showed that in all countries word reading at first grade was best predicted by letter-sound-connection, as found in other transparent orthographies. In Italy and Finland also phoneme blending, a demanding phoneme awareness skill, was a good predictor. Surprisingly, in Germany initial phoneme identification which is a basic phone awareness skill, and mother's occupation predicted first grade reading. At second grade in Finland and Germany the strongest predictors of word reading were rapid naming, in Finland also short-term-memory and in Germany and Italy reading level at the first grade. Results indicate that both orthographical and educational differences in the three countries can account for different predictors in reading.
\end{abstract}




\section{Introduction}

Cross-linguistic research may help us to better understand which factors are universal and which are orthography-specific in reading development (Seymour, Aro, \& Erskine, 2003). Among transparent orthographies (e.g. Finnish, Spanish, Greek), a phoneme is almost always spelled and pronounced the same way, whereas in deep orthographies (e.g. English, French), a phoneme can have multiple spellings, and one letter or cluster of letters can have multiple pronunciations (Ziegler \& Goswami, 2006). This variation makes it probable that the cognitive processing skills that are important for reading are not the same across different orthographies, and that the power of cognitive skills in the prediction of reading development may vary between orthographies (Landerl et al., 2013). This has an effect also on reading instruction used in different orthographies. Moreover, different preprimary activities can influence reading development (Noble et al., 2015). Parental levels of educational attainment, occupation, and income, for example, are associated with early experiences of language and literacy, which are important for reading development (Noble et al., 2015; Treiman et al., 2015). The mother's level of education, in particular, appears to be a significant predictor of reading development (Catts et al., 2001; Hecht, Burgess, Torgesen, Wagner, \& Rashotte, 2000). Finally, there is consistent evidence among international research to suggest that girls outperform boys on reading measurements across all age groups (e.g. Price-Mohr \& Price, 2017). Among children aged nine and ten, girls consistently outscore boys on international reading assessments, as indicated by the Program in International Reading Literacy Study (PIRLS), which was conducted across 49 countries in 2016 and included nine benchmarking entities (PIRLS, 2016). Is this because of instruction, education system or is it related to the cognitive skills related to reading?

This longitudinal research was completed in Finland and Germany, as well as in the SouthTyrolian area of Italy, where the majority of children (85\%) speak German as their native language. In this study, we investigate the role of phonological awareness, cognitive skills, and background factors in reading development during the first and second grades. German and Finnish orthographies are both relatively transparent. In Finnish, phonemes are read, spelled, and pronounced the same way, and the syllable structure is simple. Finnish is also a strongly inclined, agglutinating language, meaning 
that word endings appear as if they have been glued onto the body of the word, which can make for very long words. Another special feature of the Finnish language is its morphological variations, which can include both consonant and vowel variations (e.g. lammas [a sheep], lampaalle [to a sheep]) (Karlsson, 2008). These both features and can place pressure on a person's memory skills. In contrast, the German language contains many "closed" consonant-vowel-consonant syllables and complex consonant clusters (e.g. strolchst [you roam]) in both the onset and coda positions, which can create complex syllable structures and can affect the development of reading fluency and the ways in which reading difficulties manifest (Ziegler \& Goswami, 2006).

\section{Cognitive Predictors of Reading Development Among Different Orthographies}

Previous studies have pointed out several important precursors that have been established as predictors of later reading development (e.g. Landerl et al., 2013), but their relative contributions might differ across the phases of reading development and between different orthographies (Moll et al., 2014). Evidently, letter-sound connection (LSC), derived from children's knowledge of associated letter names and their phonological patterns, is one key component in learning to read (Hulme, Bowyer-Crane, Carroll, Duff \& Snowling 2012).

Several studies have shown that phonological awareness (PA) is an important component for learning how to associate sounds with letters, but its reliability as a predictor of reading skills can vary (e.g. Caravolas et al., 2012; Georgiou, Torppa, Manolitsis, Lyytinen, \& Parrila, 2012; Moll et al., 2014; Park \& Uno, 2015; Wimmer, Mayringer, \& Landerl, 2000). For example, Ziegler et al. (2010) studied predictors of second graders' reading skills in Finnish, Hungarian, Dutch, Portuguese, and French, and found that PA was the strongest significant predictor of reading accuracy and fluency across all orthographies except Finnish. PA has been shown to predict reading accuracy rather well in English and Czech (Caravolas, Volin, \& Hulme, 2005; Vaessen et al., 2010), Norwegian and Swedish (Furnes \& Samuelsson, 2009), Spanish and Slovak (Caravolas et al., 2012), and Dutch (Patel, Snowling, \& de Jong, 2004). The previous research (e.g. Dandache, Wouters, \& Ghesquière, 2014; de Jong \& van der Leij, 2003) has shown that, while learning to read, children experience greater difficulty with particular types of PA tasks, thus many studies used a total-score-only approach to PA tasks. Several years ago, Wagner, Torgesen, Laughon, Simmons, and Rashotte (1993) suggested that a 
child's ability to blend sounds into words developmentally precedes their ability to recognize individual sound segments; thus phoneme analysis may reflect a deeper level of processing that is linked to the quality of phonological representation. Hayward et al. (2017) also found that errors among different PA tasks are not random; rather, they are evidence of the knowledge and strategies the child applies while completing the task. Hayward et al. (2017) further notes that high- and lowperforming readers differ in both the degree and type of errors they make while performing PA tasks.

Rapid serial naming (RAN), the ability to name visually presented stimuli as quickly as possible, provides good sensitivity and specificity as part of the screening battery for reading development, although in regard to its relation to reading, the existing data has shown mixed results depending upon orthographical transparency. Georgiou et al. (2012) conducted a longitudinal study across three orthographies (Finnish, Greek, and English) and found that, while neither PA nor RAN (colors) were able to predict a child's reading skills during the first two years of instruction in Finnish, letter knowledge dominated reading prediction in each language. Vaessen et al. (2010) also evaluated the predictors of reading fluency across three orthographies (Hungarian, Dutch, and Portuguese) and found that, in the first and second grades, associations between PA and RAN with reading fluency were largely comparable. The previous findings imply that the association between reading and RAN is moderated by development (Peterson et al., 2017). In their study of Norwegian students, Lervåg and Hulme (2009) found that early RAN was related to later reading, but that earlier reading did not necessarily predict later RAN; similar results were found by Verhagen et al. (2015) among Dutch students, and by Wei, Georgiou, and Deng (2015) among Chinese students. Lervåg and Hulme (2009) also found that early letter knowledge influenced later naming of numbers or letters in RAN, but that naming of pictures or colors did not influence. Interestingly, Compton's (2003) longitudinal study found that early literacy influenced later RAN (numbers) for late decoders, but not for early decoders. Moreover, Wolff (2014) reported that, among Swedish students with poor decoding skills, reading speed and RAN were equal in third and fourth grades.

One key factor in learning to read is short-term memory (STM) (Hulme et al., 2012), as working memory can predict both phonological awareness and word reading efficiency (de Abreu, Gathercole, \& Martin, 2011). On the other hand, Nation and Hulme (2011) found that learning to read 
can also influence verbal STM, so the use of STM skills as a predictor of reading development is slightly contradictory.

In addition, the method of reading instruction has been shown to influence reading success and the ways in which children process print (Connelly, Thompson, Fletcher-Flinn, \& McKay, 2009). Therefore, it is important to review conclusions regarding the skills that may predict reading development within the context of reading instruction methods and the educational system (McGeown, Johnston, \& Medford, 2012; Sellès, Àvila, Martìnez, \& Ysla, 2018).

\section{Education in Three Geographic Areas}

In Finland, children begin primary school at the age of seven, and there is one additional, obligatory year of pre-primary education for six-year-old students. The national pre-primary core curriculum emphasizes building the foundation for literacy skills. Reading skills are not explicitly taught, although approximately $30 \%$ of pupils are able to decode words accurately when they begin primary school at age seven (Author, 2001). Literacy instruction Throughout the first school year students receive six hours of literacy instruction per week (Finnish National Board of Education, 2016). When reading instruction begins, children systematically begin to practice letter names and letter-sound correspondence and they learn to decode syllables, which is essential. This practice boosts children's acquisition of phonological decoding and phonemic awareness (Ziegler \& Goswami, 2006). As children's decoding skills become more automatic during the first grade, reading instruction during the second grade focuses more on practicing word and sentence reading fluency and reading comprehension (Finnish National Board of Education, 2016). In Finland, special needs education is primarily provided within mainstream schools.

In Germany, school attendance is obligatory at the age of six. Approximately $90 \%$ of fiveyear-old children attend kindergarten before entering primary school. In Hessen (where this study was completed), although literacy education is mentioned in the curriculum, PA is not specifically emphasized in kindergarten. Five hours of reading and writing instruction are provided each week in the first and second grades (Hessisches Kulturministerium, 2016). Between schools, and sometimes even within each school, different approaches and teaching methods are used for reading instruction, though the teachers who participated in this study used phonics-based methods of reading instruction. 
The Hessen area allows for the inclusion of students with special needs into mainstream schools, but special schools are also available.

In South Tyrol, Italy, German is the preferred language of instruction in this region. Preprimary education is provided for children aged three to six, though this is not compulsory. Students usually begin primary school at the age of six, but students who were born between January and March and who are still five years old when the school year begins may access primary school slightly earlier than their peers; this is known as Primina. During pre-primary education, training in PA is very common in preparation for reading and writing (Fthenakis, 2008) and, during the first two years of primary school, approximately six hours of reading and writing instruction are provided each week (Larcher \& Zandonella, 2012). There are no specific guidelines regarding which method should be used to teach reading and writing in primary school, but most teachers (including those who participated in this study) use phonics-based instruction. A single curriculum, established at the national level, is common across all levels of education (PIRLS, 2016). Among European countries, Italy has the highest rate of inclusion of students with special needs within mainstream schools.

\section{The Aim of this Study}

The critical issue addressed in this study is whether the same cognitive ( $\mathrm{PHB}=$ phoneme blending, IPHI = initial phoneme identification, $\mathrm{SB}=$ syllable blending, $\mathrm{SS}=$ syllable segmentation, and LSC) and background (gender, age, language, mother's occupation) factors can predict reading skills within a very transparent orthography (Finnish), as well as in a less transparent orthography (German) that is taught in two different educational systems. The research questions were as follows:

1. Do PHB, IPHI, SB, SS and LSC account for unique predictive effects on word reading in the first grade when the effects of the child's gender, age, language, and mother's occupation are controlled?

2. Do PHB, IPHI, SB, SS and LSC, RAN (letters and pictures), STM (forward and backward), and word reading measured at the first grade account for unique predictive effects on word reading in the second grade when the effects of the child's gender, age, language, and mother's occupation are controlled? 


\section{Participants}

Three groups of children, all of whom were starting first grade, were followed throughout this study.

The Finnish group consisted of 324 children (153 girls, 171 boys), with a mean age of 7.11 years (SD 0.25) at the beginning of first grade. The children were enrolled in 12 schools and 21 separate classes in a town in central Finland, and the majority of students (97.4\%) were native Finnish speakers. Regarding their mothers' occupational status, $19.1 \%$ worked in highly responsible occupations (e.g. physicians, engineers), 53.6\% were qualified workers (e.g. secretaries, nurses), and $27.2 \%$ were unqualified workers or were unemployed.

The German group consisted of 283 children (123 girls, 160 boys), with a mean age of 6.66 years (SD 0.39) at the beginning of first grade. Students were enrolled in seven different schools and 13 classes in the Hessen area. The majority of participants (77.7\%) spoke German as their native language, and $21.3 \%$ spoke German as well as another language. Regarding their mothers' occupational status, $17.3 \%$ worked in highly responsible occupations, $38 \%$ were qualified workers, and $12.7 \%$ were unqualified workers or were unemployed.

The Italian group consisted of 162 children ( 87 girls, 75 boys), with a mean age of 6.18 years (SD 0.30) at the beginning of first grade. Students were enrolled in ten schools and ten separated classes in South Tyrol. The majority of participants (79\%) spoke German as their native language, and $21 \%$ spoke German as well as another language. Regarding their mothers' occupational status, $19.1 \%$ worked in highly responsible occupations, $46.3 \%$ were qualified workers, and $21.6 \%$ were unqualified workers or were unemployed.

\section{Procedure and Materials}

Before beginning of this study, all PA and LSC measures and procedures were pilot-tested with first-grade children in three countries (Finland, Germany, Italy). Other measures, including reading tests, RAN, and STM tests, are widely-used and have been standardized across both the Finnish and German languages. Tests were administered by local testers who were trained by the study researchers. Written instructions were provided to ensure that testers administered the tests in the prescribed manner and in the same order. The full testing time was approximately 60 minutes, 
including small breaks. Each task included three practice items. Due to limited resources, the LSC, PA, and reading tests were administered as group tests within each class, while the STM and RAN tests were administered individually for each child, but were only completed during second grade.

In each country, the first testing period (LSC, IPHI, PHB, SB, and SS tests) was scheduled exactly eight weeks after the children began first grade (September or October, depending on when the school year began). The reading test (WR1) was administered exactly 18 weeks later (around February, depending on the length of each country's holiday break). The same procedure was repeated in second grade, with RAN and STM tests administered in February and the WR2 test in May (after 29 weeks of education). At the beginning of the study, the children's parents and teachers were asked to provide written consent for their participation.

Letter-sound connection. For the LSC test, children were provided with an A4 sheet containing empty boxes. The tester pronounced a phoneme twice and students were asked to write the appropriate letter in each corresponding box, using either upper or lowercase letters. The Finnish LSC test incorporated 23 letter sounds (Authors, 2010a), while the German test incorporated 26 sounds (Authors, 2010b). The German language contains 26 letters, as well as three umlauts (ä, ö, ü) and, in lowercase, the Eszett (ß); however, for clarity, only 26 letter sounds were used. Cronbach's alphas were good in all countries, namely .926 for the Finnish data, .916 for the German data, and .919 for the Italian data.

Initial phoneme identification (IPHI) task. The children were each given an A4 sheet containing ten rows, each with four pictures of common objects (words of four to six letters); printed underneath each picture was a smiley face. The children were then instructed as follows: "Here are pictures of an apple, a sock, a bird, and a bag. Which word starts with the phoneme /s/?" The children were instructed to color the corresponding smiley face after making their decision. The sum score was based on the number of correct answers (maximum of ten). On the Finnish test (Lerkkanen, Poikkeus, \& Ketonen, 2006; modified by Authors, 2010a), the reliability score was only .698; on the German test the reliability score was .780; and on the Italian data, the score was .816 (Authors, 2010b).

Syllable segmentation task (SS). The children were each given an A4 sheet containing ten pictures of common nouns (of one to four syllables). Printed underneath each picture was a hand with 
five fingers. The children were given the following instructions: "Picture 1: Look at the first picture. It is a dolphin. Now silently count how many syllables there are in the word 'dolphin' and color the same number of fingers on the hand." The total score was the sum of correct answers (maximum of ten). Cronbach's alphas were quite good, namely .788 for the Finnish test (Authors, 2010a), .825 for the German test and .766 for the Italian data (Authors, 2010b),

Syllable blending task (SB). The children were each given an A4 sheet containing 10 rows, each with three pictures of common objects (words of two to three syllables); printed underneath each picture was a smiley face. The children were instructed as follows: "Look at the pictures in the first row. I will say one of these words in parts (using syllables). Which word am I saying?" The students were instructed to color the corresponding smiley face after making their decision. The total score was the sum of correct answers (maximum of ten). Cronbach's alpha was .884 for the Finnish test (Authors, 2010a), .893 for the German test and .755 for the Italian children (Authors, 2010b).

Phoneme blending task (PHB). The children were each given an A4 sheet containing ten rows, each with three pictures of common nouns (of four to six letters); printed underneath each picture was a smiley face. Students were given the following instructions: "Row 1: Listen to the words you hear on the CD. They are pronounced phoneme by phoneme. Each word you hear corresponds with one of the pictures in the first row. After you have chosen the right picture, color the smiley face underneath that picture." The total score was the sum of correct answers (maximum of ten). Cronbach's alpha was .755 for the Finnish test (Authors, 2010a), .724 for the German test and .798 for the Italian data (Authors, 2010b)

Auditory short-term memory (STM). The Digit Span sub-test from the Wechsler Intelligence Scale for Children (WISC-IV) (Wechsler, 2003) was administered to measure short-term memory skills. The analyzed tasks included both digits forward and digits backward and the results were standardized for each dataset (Italian, German, and Finnish) due to the varying lengths of number names in Finnish and German.

Rapid automatized naming (RAN). Based on the rapid serial naming test (Dencla \& Rudell, 1974), two sub-tests were executed to test the time it took each child to name letters and objects. The 
time each child spent answering the questions was standardized for each dataset (Italian, German, and Finnish) due to the varying lengths of number names in Finnish and German.

Reading. In Finland, a group-administered test from the nationally standardized battery of reading tests (ALLU - Reading Test for Primary School) was used to assess word-level reading skills (Lindeman, 1998). A maximum of 80 trials could be administered within a five-minute time limit in first grade (WR1), or within a two-minute time limit in second grade (WR2). Each item included a picture and four phonologically similar words. The children's task was to draw a line between a picture and the semantically matching word. Word-level reading variables were constructed by calculating the number of correct responses in each phase (one point was given for each correct answer). The Cronbach's alphas were .976 for WR1 and .962 for WR2.

For the German-speaking groups, one sub-test from a standardized group test (ELFE, a Reading Comprehension Test for Grades 1-6) was used to assess word-level reading skills (Lenhard $\&$ Schneider, 2006). Each item included a picture and four phonologically similar words. The children's task was to draw a line under the word that semantically matched the picture. A maximum of 72 words could be read within three minutes. Word-level reading variables were constructed by calculating the number of correct responses in each phase (one point was given for each correct answer). For the German data, Cronbach's alphas were .953 for WR1 and .955 for WR2. For the Italian data, Cronbach's alphas were .890 for WR1 and .959 for WR2.

Mother's occupation. As we were not able to collect reliable and comparative information regarding the parents' levels of education, only the parents' occupations were asked. This study used only the mothers' occupations. For the Finnish and Italian data, mothers reported their occupations on a questionnaire; for the German data, teachers requested this information directly from the mothers. For this study, a variable was created to measure the mothers' occupations using an ordinal scale, where $1=$ a highly responsible occupation, $2=$ a qualified worker, and $3=$ an unqualified or unemployed worker.

Child's age. As we found that the Italian students were significantly $(\mathrm{p}<.001)$ younger than were the Finnish and German students, age was involved in the regression analyses; however, the size of this effect was quite small. 
Child's gender. The gender variable was formed using a categorical scale, where $1=$ female and $2=$ male

Child's language. The language variable was formed using a categorical scale, where $0=$ Finnish or German, and $1=$ Finnish or German and another language.

\section{Statistical Analyses}

As a preliminary procedure for SPSS (Version 25.0), the distribution of all variables was controlled and the skewed variables were normalized using an inverse function for IPHI, LSC, PHB, SB, SS, RAN (letters and pictures), and WR2 for the Finnish data. Among the German data, an inverse function was used to normalize IPHI, SB, SS, and RAN (letters and pictures), and a logarithmic transformation was performed for WR1. Among the Italian data, an inverse function was used to normalize IPHI, PHB, SB, and RAN (letters and pictures), and a logarithmic transformation was used for LSC. Thereafter, all variables were standardized by country.

Missing information within the categorical variables (child's language, mother's occupation) was investigated by checking whether the children exhibited any differences in reading skills when there was missing information about their language and their mothers' occupations, compared to the reading skills of those children who were not missing any information from the same variables. The German data showed that, where information about the child's language was missing, children exhibited significantly weaker reading skills in first grade, compared to children who were not missing the same information $(\mathrm{t}=-2.466, \mathrm{df}=245, \mathrm{p}=.014)$. This difference was not apparent among children in second grade $(\mathrm{t}=.165, \mathrm{df}=237, \mathrm{p}=.869)$. Among Finnish and Italian children, no differences were apparent between these groups. When reading skills were compared between children with missing information about their mother's occupation, no significant differences were found among German and Italian children. The Finnish data showed that, where information about a mother's occupation was missing, children exhibited significantly weaker reading skills in first grade $(\mathrm{t}=-2.623, \mathrm{df}=274, \mathrm{p}=.009)$, compared to those children who were not missing this information. This difference was not apparent among children in second grade $(\mathrm{t}=-1.868, \mathrm{df}=284, \mathrm{p}=.063)$.

Missing information was replaced with median values for these categorical/ordinal variables, which caused slight changes to become apparent within the mean and standard deviations for these 
variables. The mean value for the child's language, in the original data versus the missing values replaced by the median, changed the German data from $.25(\mathrm{SD}=.43)$ to $.24(\mathrm{SD}=.43)$. The mean value for the mother's occupation, in the original data versus the missing values replaced by the median, changed the Finnish data from $.05(\mathrm{SD}=.32)$ to $.04(\mathrm{SD}=.28)$.

Missing information regarding predictive variables and reading skills were also checked (Table 1). No information about the children's ages was missing for any of the three countries. For the purpose of handling missing information, differences among the children's reading skills were tested among students who were missing information about IPHI, LSC, PHB, SB, and SS; cognitive skills were also tested using RAN (letters and pictures) and STM (forward and backward). Table 2 shows the results of the t-tests, separated by country. Based on these results, the participants with missing values for all phonological awareness variables - LSC, RAN (letters and pictures), and STM (forward and backward) - were dropped from the analysis.

--- Table 1 about here---

---Table 2 about here---

Finally, a missing values analysis (MVA) was carried out using Little's MCAR test for SPSS (Version 25), which revealed that missing values for WR1 and WR2 were apparent among the Finnish data $\left(X^{2}=.962, \mathrm{df}=2, \mathrm{p}=.618\right)$, German data $\left(\mathrm{X}^{2}=4.489, \mathrm{df}=2, \mathrm{p}=.106\right)$, and Italian data $\left(\mathrm{X}^{2}=\right.$ $.930, \mathrm{df}=2, \mathrm{p}=.628$ ). In the next step, a fully conditional specification (an iterative Markov chain Monte Carlo $[\mathrm{MCMC}]$ ) was used as the method of imputation. For each country, the remaining missing values from IPHI, LSC, PHB, SB, SS, and WR1 were imputed and used as predictors; WR2 was imputed only as a dependent variable. Separate imputations were carried out a total of 20 times for each country to provide pooled descriptive statistics and correlations, and to highlight the significance of the coefficients (significant predictors) in the pooled model. Imputation does not provide a pooled result for ANOVA (IBM Knowledge Center, 2019).

To answer the research questions, we used two linear regression models, using the stepwise method, with probability-of-F-to-enter values of .05 and .10 for remove. During analysis, the data was split by imputation number and compared for each group. First, the effects of gender, age, child's language, mother's occupation, IPHI, LSC, PHB, SB, and SS on WR1 were analyzed separately for 
each country. Second, the effects of gender, age, child's language, mother's occupation, IPHI, LSC, PHB, SB, SS, and WR1 on WR2 were analyzed separately for each country.

\section{Results}

The descriptive statistics for the test scores and background variables are presented in Table 3.

--- Table 3 about here ---

The correlations for Finnish and German children are presented in Table 4, and those for Italian children in Table 5. The correlations between PA variables (excluding SS) and LSC were strongest within the German data and weakest within the Finnish data. The same phenomenon was observed in the correlations between STM and PA variables and LSC. WR1 and WR2 were strongly correlated among the German and Italian data; among the Finnish data, the correlation was not significant. For all three countries, WR1 and WR2 were either modestly or weakly correlated with PA variables, with the strongest correlation appearing between WR1 and LSC. WR1 and WR2 were significantly correlated with STM variables and RAN among the German and Italian data.

--- Insert Table 4 about here ---

--- Insert Table 5 about here ---

\section{The Effects of a Child's Gender, Age, Language, Mother's Occupation, IPHI, PHB, LSC, SB, and SS on WR1}

To answer the first research question, a stepwise regression model was developed to analyze the effects of each child's gender, age, mother's occupation, IPHI, PHB, LSC, SB, and SS on WR1. Twenty different imputed regression models, in addition to the original data model, were obtained for each country. The Finnish dataset included two to three model with significant F-test results $(p=.000$ in each), while the German data included four to six model with significant F-test results ( $p=.000$ in each), and the Italian data included two models with significant F-test results ( $p=.000$ in each). These results illustrate that the mother's occupation only made a significant contribution among the German data $(\mathrm{t}=-3.209, \mathrm{p}=.001)$, where a high maternal occupational level increased the probability of students demonstrating good WR1 skills. According to the pooled predictors, among the Finnish data, the best predictor of WR1 success was LSC $(\mathrm{t}=5.676, \mathrm{p}=.000)$; when children exhibited better 
letter-sound connection skills, they were more likely to also show better word-level skills. In addition, good PHB skills $(\mathrm{t}=3.978, \mathrm{p}=.000)$ were associated with good WR1 skills. Among the Finnish data, approximately $24-26 \%$ of WR1results can be explained with this model.

Among the German data, the best predictor of WR1 success was also LSC $(\mathrm{t}=5.031, \mathrm{p}=$ $.000)$, and the second-best predictor was IPHI $(\mathrm{t}=3.038, \mathrm{p}=.002)$, meaning that when children exhibited better LSC and IPHI skills, their WR1 skills were also likely to be better. Among the German sample, the explanation rate for different data varied between 27-32\%.

Among the Italian data, the best predictor of WR1 success was also LSC $(\mathrm{t}=4.805, \mathrm{p}=.000)$, indicating that, when children displayed stronger LSC skills, their WR1 skills were likely to also be stronger. In addition, Italian children who exhibited better PHB skills $(t=3.312, p=.001)$ also tended to display stronger WR1 skills. Among the Italian data, approximately $24-26 \%$ of WR1 results can be explained with this regression model.

Children's ages and languages were not significant predictors of WR1 performance in any of the included countries.

\section{The Effects of a Child's Gender, Age, Language, Mother's Occupation, IPHI, PHB, LSC, SB, SS, RAN, STM, and WR1 on WR2}

To answer the second research question, a stepwise regression model was developed to analyze the effects of a child's gender, age, language, mother's occupation, IPHI, PHB, LSC, SB, SS, RAN (letters and pictures), STM (forward and backward), and WR1 on WR2. Twenty different imputed regression models were obtained for each country, in addition to the original data model. The Finnish data included two models with significant F-test results $(\mathrm{p}=.000$ in each), while the German data included two to three models with significant F-test results $(\mathrm{p}=.000$ in each), and the Italian data included four to six models/data with significant F-test results $(\mathrm{p}=.000$ in each). These results indicate that RAN letters $(t=5.070, p=.000)$ was the best predictor of good WR2 skills among Finnish children. Among the Finnish data, the second-best predictor of WR2 success was STM backward $(\mathrm{t}=3.044, \mathrm{p}=.002)$. WR1 was a significant predictor of WR2 results among both the German $(t=9.749, \mathrm{p}=.000)$ and the Italian datasets $(\mathrm{t}=9.980, \mathrm{p}=.000)$. Among German children, RAN letters $(\mathrm{t}=4.895, \mathrm{p}=.000)$ was also a good predictor of WR2 skills. These measurements were 
able to predict the WR2 skills for 14-16\% of Finnish children, 41-46\% of German children, and 55$57 \%$ of Italian children. Children's ages, languages, and their mothers' occupations were not significant predictors of WR2 skills in any of the included countries.

\section{Discussion}

The present study contributes to the existing literature and educational field about children's literacy development by examining the predictors of reading skills among two transparent orthographies (German and Finnish) and across three educational systems (Finnish, German, and Italian). Based on our results, it seems probable that the cognitive processing skills that are important for reading development in the first and second grades are dependent upon orthographical transparency and on the different educational systems.

The results of this study indicate that children's knowledge of associated letter names and their phonological patterns seem to be the most important predictor of first-grade reading skills across all countries and orthographies; this result has also been illustrated in less transparent orthographies (e.g. Hulme et al., 2012), as well as in other transparent orthographies (Caravolas et al., 2012; Furnes \& Samuelsson, 2009; Moll et al., 2012). This finding may be related to the effects of the transparent orthographies studied here as good letter knowledge allows children to accurately decode which letters correspond with which sounds in a highly predictable manner (Caravolas et al., 2013). Thus, there were differences in the mean levels of LSC task performance within the German-speaking areas, as German children recognized less than $50 \%$ of letter sounds at the beginning of first grade, while Italian children recognized, on average $73 \%$ of letter sounds. This finding may be explained by the fact that, in Italy, more instruction in phonological awareness is provided during pre-primary education.

As there were four different phonological awareness measures, it was interesting to discover the inter-correlations between these measures and how they correlated with the reading measures. In each dataset, PHB showed the highest correlation with WR1, indicating that the task of phoneme blending is quite similar to the task of decoding (e.g. Author, 2001). Other correlations between PA measures and reading tasks among the Finnish and Italian samples were low or were not significant, while the mean scores for the PA measures were higher, close to the ceiling effect. One surprising 
result was the rather low mean score for the SS task among Italian and German children, especially considering that Wimmer, Landerl, Linortner, and Hummer (2000) found that German preschoolers were able to perform the syllable segmentation task with $81 \%$ accuracy in 1991 . The Finnish syllable structure is rather simple, which may explain the better SS task results among the Finnish sample. Another interesting finding among the German results was the increased correlation between IPHI and both reading measures, and the fact that WR1 was best predicted by IPHI; among the Italian and Finnish data, WR1 was best predicted by PHB. This might indicate that, in the first grade, German children exhibit different levels of phonological knowledge in their reading tasks (Dandache et al., 2014; Hayward et al., 2017).

Finally, similar to the results of a study conducted by Hecht et al. (2000), among the German data, good reading skills in the first grade were significantly predicted by a mother's highly responsible occupation. Why was this only true in Germany? The proportion of mothers who identified as highly responsible workers in each country was very similar, but in Germany, the proportion of mothers who identified as unqualified workers was significantly lower than in Finland and Italy.

We also predicted children's reading skills in the second grade (WR2) using the same tests for PA, LSC, and WR1, as well as the same background predictors as in the first research question, along with RAN and STM, which were measured in the middle of the second grade. It is interesting, and in line with previous research about transparent orthographies, that none of the PA nor LSC measurements had a significant predicting effect on WR2, although PHB maintained a rather strong correlation with WR2 among the Finnish data. Instead, RAN letters was the most significant predictor of WR2 across all three countries, which suggests that RAN may make a unique contribution to variances in word reading fluency. Interestingly, among German and Italian children, WR1 and WR2 were highly correlated (.63-.69), and WR1 was able to predict WR2 skills, which shows the linear development of reading skills in both countries. This was not the case among the Finnish sample, as children's progression in learning the highly consistent Finnish orthography appears limited to the first grade. At the beginning of primary education, approximately $30 \%$ of Finnish children are able to read fluently and accurately, while the remaining $70 \%$ are mostly unable to read; however, after one 
year or less than one year, most children are able to read fluently (in our study, the mean WR2 score was 70 and the maximum score was 80). This result has been documented in many Finnish studies (e.g. Aro, 2017; Leppänen, Niemi, Aunola, \& Nurmi, 2004; Parrila, Aunola, Leskinen, Nurmi, \& Kirby, 2005). Among Finnish children, WR2 was best predicted by working memory skills (STM backward), which may be connected to the fact that Finnish words are rather long and place undue pressure on the working memory of beginner readers' decoding skills.

\section{Conclusion}

The present longitudinal study, spanning two years, identified the most important predictors of reading skills in the first and second grade among three samples of children in Finland, Germany, and Italy (South Tyrol). On average, Finnish children exhibited relatively high mean scores in reading after receiving phonics-based reading instruction for half a year. First grade reading skills were best predicted by LSC and PHB, while second grade reading skills were best predicted by RAN and STM. German and Italian children exhibited roughly similar reading abilities in the middle of the first grade, but the predictors of their reading success were different. These results indicate that, when making assumptions about the predictors of reading skills across different orthographies, it is necessary to first assess what is meant by the term, orthographical transparency, rather than simply classifying orthographies as either transparent or deep. More research is needed in order to draw conclusions about longitudinal predictors and how educational differences can affect reading skills.

\section{Limitations}

As in any cross-linguistic study, a major issue in the present study is the extent to which linguistic tasks that are designed for different languages can tap similar cognitive processes and represent similar levels of difficulty. It is clear that, although the selected cognitive and reading measures were similar for each different orthography, and although these measures were pilot-tested, the first limitation that should be mentioned is that the tasks were not exactly the same between orthographies, and the reading tests did not involve oral reading. The second limitation that should be mentioned is that the Cronbach's alphas measuring IPHI among the Finnish data was much lower than alphas in other countries showing some inconsistency of the measurement. 


\section{References}

Author (2001). [details removed for peer review]

Authors (2010a). [details removed for peer review]

Authors (2010b). [details removed for peer review]

Aro, M. (2005). Learning to read: The effect of orthography. In R. M. Joshi \& P. G. Aaron (Eds.), Handbook of orthography and literacy (pp. 531-550). London, UK: Lawrence Erlbaum.

Baker, C. E. (2013). Fathers' and mothers' home literacy involvement and children's cognitive and social emotional development: Implications for family literacy programs. Applied Developmental Science, 17(4), 184-197.

Caravolas, M., Volin, J., \& Hulme, C. (2005). Phoneme awareness is a key component of alphabetic literacy skills in consistent and inconsistent orthographies: Evidence from Czech and English children. Journal of Experimental Child Psychology, 92(2), 107-139.

Caravolas, M., Lervåg, A., Defior, S., Málková, G. S., \& Hulme, C. (2013). Different patterns, but equivalent predictors, of growth in reading in consistent and inconsistent orthographies. Psychological Science, 24(8), 1398-1407.

Caravolas, M., Lervåg, A. Mousikou, P., Efrim, C., Litavský, M., Onochie-Quintanilla, E., ... Hulme, C. (2012). Common patterns of prediction of literacy development in different alphabetic orthographies. Psychological Science, 23(6), 678-686.

Catts, H. W., Fey, M. E., Zhang, X., \& Tomblin, J. B. (2001). Estimating the risk of future reading difficulties in kindergarten children. Language, Speech, and Hearing Services in Schools, 32, $38-50$.

Compton, D. (2003). Modeling the relationship between growth in rapid naming speed and growth in decoding skill in first-grade children. Journal of Educational Psychology, 95, 225-239.

Connelly, V., Thompson, G. B., Fletcher-Flinn, C. M., \& McKay, M. F. (2009). Does the type of reading instruction have an influence on how readers process print? In C. Wood \& V. Connelly (Eds.), Contemporary perspectives on reading and spelling (pp. 239-253). Abingdon, Oxon, UK: Routledge. 
Dandache, S., Wouters, J., \& Ghesquière, P. (2014). Development of reading and phonological skills of children at family risk for dyslexia: A longitudinal analysis from kindergarten to sixth grade. Dyslexia, 20(4), 305-329.

de Abreu, P. M. J. E., Gathercole, S. E., \& Martin, R. (2011). Disentangling the relationship between working memory and language: The roles of short-term storage and cognitive control. Learning and Individual Differences, 21(5), 569-574.

de Jong, P. F., \& van der Leij, A. (2003). Developmental changes in the manifestation of a phonological deficit in dyslexic children learning to read a regular orthography. Journal of Educational Psychology, 95, 22-40.

Dencla, M., \& Rudel, R. (1974). Rapid "automatized" naming of pictured objects, colors, letters and numbers by normal children. Cortex, 10(2), 186-202.

Finnish National Board of Education. (2016). Retrieved from http://www.oph.fi/english/education_system

Fthenakis, W. E. (2008). Bildung von anfang an: Bildungskonzepte für kinder unter sechs jahren aus internationaler und nationaler perspective [Education from the beginning: Educational concepts for children under the age of six from an international and national perspective]. In M. Hoppe \& A. Schack (Eds.). Rohstoff bildung: Lebenslang lernen. Wiesbadener gespräche zur sozialpolitik [Lifelong learning: Wiesbaden talks on social policy]. Heidelberg, Germany: Curt Haefner Verlag.

Furnes, B., \& Samuelsson, S. (2010). Predicting reading and spelling difficulties in transparent and opaque orthographies: A comparison between Scandinavian and US/Australian children. Dyslexia, 16(2), 119-142.

Georgiou, G. K., Torppa, M., Manolitsis, G., Lyytinen, H., \& Parrila, R. (2012). Longitudinal predictors of reading and spelling across languages varying in orthographic consistency. Reading and Writing: An Interdisciplinary Journal, 25(2), 321-346.

Hayward, D. V., Annable, C. D., Fung, J. E., Williamson, R. D., Lovell-Johnston, M. A. A., \& Phillips, M. L. (2017). Beyond the total score: A preliminary investigation into the types of 
phonological awareness errors made by first graders. Early Childhood Education Journal, 45, 809-820.

Hecht, S. A., Burgess, S. R., Torgesen, J. K., Wagner, R. K., \& Rashotte, C. A. (2000). Explaining social class differences in growth of reading skills from beginning kindergarten through fourth-grade: The role of phonological awareness, rate of access, and print knowledge. Reading and Writing, 12, 99-128.

Hessisches Kulturministerium [Hessian Ministry of Culture]. (2016). Retrieved from https://verwaltung.hessen.de/irj/HKM_Internet.

Hulme, C., Bowyer-Crane, C., Carroll, J. M., Duff, F., \& Snowling, M. J. (2012). The causal role of phoneme awareness and letter-sound knowledge in learning to read: Combining intervention studies with mediation analyses. Psychological Science, 23, 572-577.

IBM Knowledge center. (2019). Analyzing Multiple Imputation Data. Retrieved from https://www.ibm.com/support/knowledgecenter/en/SSLVMB_24.0.0/spss/mva/mi_analysis.ht $\underline{\mathrm{ml}}$

Karlsson, F. (2008). Yleinen kielitiede [General linguistics]. Helsinki, Finland: Gaudeamus.

Landerl, K., Rasmus, F., Moll, K., Lyytinen, H., Leppänen, P. H. T., Lohvansuu, K.... Schulte-Körne, G. (2013). Predictors of developmental dyslexia in European orthographies with varying complexity. Journal of Child Psychology and Psychiatry, 54(6), 686-694.

Larcher, E., \& Zandonella, M. (2012). Ursachen unterschiedlicher schülerinnenleistungen in Tirol und Südtirol [Reasons for students' different achievement in Tyrol and South Tyrol]. Vienna, Austria: SORA Institute for Social Research and Consulting.

Lenhard, W., \& Schneider, W. (2006). ELFE 1-6. Ein leseverständnistest für erst-bis sechstklässler [Reading tests for students from first through sixth grade]. Göttingen, Germany: Hogrefe.

Leppänen, U., Niemi, P., Aunola, K., \& Nurmi, J.-E. (2004). Development of reading skills among preschool and primary school pupils. Reading Research Quarterly, 39, 72-93.

Lerkkanen, M.-K., Poikkeus, A.-M., \& Ketonen, R. (2006). ARMI. Luku- ja kirjoitustaidon arviointimateriaali 1. luokalle [Assessing reading and spelling in the first grade]. Helsinki, Finland: WSOY. 
Lervåg, A., \& Hulme, C. (2009). Rapid Automatized Naming (RAN) taps a mechanism that places constraints on the development of early reading fluency. Psychological Science, 20, 1040 1048.

Lindeman, J. (1998). ALLU-ala-asteen lukutesti [ALLU: Reading test for primary school].

Turku, Finland: Centre for Learning Research, University of Turku.

McGeown, S. P., Johnston, R. S., \& Medford, E. (2012). Reading instruction affects the cognitive skills supporting early reading development. Learning and Individual Differences, 22(3), 360364.

Moll, K., Ramus, F., Bartling, J., Bruder, J., Kunze, S., Neuhoff, N., ... Landerl, K. (2014). Cognitive mechanisms underlying reading and spelling development in five European orthographies. Learning and Instruction, 29, 65-77.

Noble, K. G., Houston, S. M., Brito, N. H., Bartsch, H., Kan, E., Kuperman, J.M....Mostofsky, S. (2015). Family income, parental education and brain structure in children and adolescents. Nature Neuroscience, 18(5), 773-778.

Park, H.-R., \& Uno, A. (2015). Cognitive abilities underlying reading accuracy, fluency and spelling acquisition in Korean Hangul learners from grades 1 to 4: A cross-sectional study. Dyslexia, $21,235-253$.

Parrila, R., Aunola, K., Leskinen, E., Nurmi, J., \& Kirby, J. (2005). Development of individual differences in reading: Results from longitudinal studies in English and Finnish. Journal of Educational Psychology, 97, 299-319.

Patel, T., Snowling, M. J., \& de Jong, P. F. (2004). A cross-linguistic comparison of children learning to read in English and Dutch. Journal of Educational Psychology, 96, 785-797.

Peterson, R. L., Arnett, A. B., Pennington, B. F., Byrne, B., Samuelsson, S., \& Olson, R. K. (2017). Literacy acquisition influences children's rapid automatized naming. Developmental Science, 21(3), 1-9.

PIRLS. (2016). Encyclopedia. Retrieved from http://timssandpirls.bc.edu/pirls2016/encyclopedia/.

Poulsen, M., Juul, H., \& Elbro, C. (2015). Multiple mediation analysis of the relationship between rapid naming and reading. Journal of Research in Reading, 38(2), 124-140. 
Price-Mohr, R., \& Price, C. (2017). Gender differences in early reading strategies: A comparison of synthetic phonics only with a mixed approach to teaching reading to 4-5 year-old children. Early Childhood Education Journal, 45, 613-620.

Reichen, J. (2001). "Hannah hat kino im kopf": Die Reichen methode lesen durch schreiben und ihre hintergründe für lehrerinnen und lehrer, studierende und eltern ["Hannah has a cinema in her head": A Reichen method for reading through writing and theory for teachers, students and parents]. Hamburg, Germany: Heinevetter-Verlag.

Schaars, M. M. H., Segers, E., \& Verhoeven, L. (2017). Word decoding development during phonics instruction in children at risk for dyslexia. Dyslexia, 23(2), 141-160.

Sellès P., Àvila, V., Martìnez, T., \& Ysla, L. (2018). The skills related to the early reading acquisition in Spain and Peru. PLoS ONE, 13(3): e0193450. https://doi.org/10.1371/journal.pone.0193450.

Sénéchal, M., \& LeFevre, J. (2002). Parental involvement in the development of children's reading skills: A 5-year longitudinal study. Child Development, 73(2), 445-460.

Seymour, P. H. K., Aro, M., \& Erskine, J. M. (2003). Foundation literacy acquisition in European orthographies. British Journal of Psychology, 94(2), 143-174.

Treiman, R., Schmidt, J., Decker, K., Robins, S., Levine, S. C., \& Demir, Ö. E. (2015). Parents' talk about letters with their young children. Child Development, 86(5), 1406-1418.

Vaessen, A., Bertrand, D., Tóth, D., Csépe, V., Faísca, L., Reis, A., \& Blomert, L. (2010). Cognitive development of fluent word reading does not qualitatively differ between transparent and opaque orthographies. Journal of Educational Psychology, 102(4), 827-842.

von Suchodoletz, A., Larsen, R. A. A., Gunzenhauser, C., \& Fäsche, A. (2015). Reading and spelling skills in German third graders: Examining the role of student and context characteristics. British Journal of Educational Psychology, 85, 533-550.

Wagner, R. K., Torgesen, J. K., Laughon, P., Simmons, K., \& Rashotte, C. A. (1993). Development of young readers' phonological processing abilities. Journal of Educational Psychology, 85, 83-103. 
Wechsler, D. (2003). Manual for the Wechsler preschool and primary scale of intelligence (revised ed.). New York, NY: Psychological Corporation.

Wei, W., Georgiou, G. K., \& Deng, C. (2015). Examining the cross-lagged relationships between RAN and word reading in Chinese. Scientific Studies of Reading,19(6), 446-455.

Wimmer, H., Mayringer, H., \& Landerl, K. (2000). The double deficit hypothesis and difficulties in learning to read a regular orthography. Journal of Educational Psychology, 92, 668-680.

Wolff, U. (2014). RAN as a predictor of reading skills, and vice versa: Results from a randomised reading intervention. Annals of Dyslexia, 64(2), 151-165.

Ziegler, J. C., Bertrand, D., Tóth, D., Csépe, V., Reis, A., Faisca, L.... Blomert, L. (2010).

Orthographic depth and its impact on universal predictors of reading: A cross-language investigation. Psychological Science, 21(4), 551-559.

Ziegler, J. C., \& Goswami, U. (2006). Becoming literate in different languages: Similar problems, different solutions. Developmental Science, 9(5), 429-453. 
Table 1. Missing information from the original data.

\begin{tabular}{l|c|c|c|c|c|c}
\hline & \multicolumn{2}{c}{ Finnish pupils } & \multicolumn{2}{c}{ German pupils } & \multicolumn{2}{c}{ Italian pupils } \\
& \multicolumn{2}{c}{ Missing all } & \multicolumn{2}{c}{ Missing all } & \multicolumn{2}{c}{ Missing all } \\
& $\mathrm{n}$ & $\%$ & $\mathrm{n}$ & $\%$ & $\mathrm{n}$ & $\%$ \\
\hline IPHI, LSC, PHB, SB, SS & 18 & 5.6 & 26 & 9.2 & 4 & 2.5 \\
\hline RAN (letters, pictures), STM & & & & & & \\
(forward, backward) & 46 & 14.3 & 31 & 12.1 & 9 & 5.7 \\
\hline WR1 & 45 & 14.0 & 35 & 12.4 & 13 & 8.0 \\
\hline WR2 & 35 & 10.9 & 43 & 15.2 & 13 & 8.0 \\
\hline Child's language & 86 & 26.8 & 29 & 10.3 & 0 & 0.0 \\
\hline Mother's occupation & 86 & 26.8 & 89 & 31.6 & 20 & 12.3 \\
\hline
\end{tabular}


Table 2. Mean differences between reading groups with and without missing information about phonological awareness (IPHI, LSC, PHB, SB, SS), RAN (letters and pictures), and STM (forward and backward).

Missing information for all phonological awareness variables

\begin{tabular}{c|c|c|c|r|r|r|r|r|r}
\hline & \multicolumn{4}{|l|}{ Finnish children } & \multicolumn{4}{l|}{ German children } & \multicolumn{2}{l}{ Italian children } \\
\cline { 2 - 10 } & $\mathrm{t}$ & \multicolumn{1}{l|}{$\mathrm{df}$} & $\mathrm{p}$ & $\mathrm{t}$ & $\mathrm{df}$ & $\mathrm{p}$ & $\mathrm{t}$ & $\mathrm{df}$ & $\mathrm{p}$ \\
\hline WR2 & -0.097 & 274 & 0.923 & 0.638 & 10.46 & 0.537 & -2.142 & 146 & 0.034 \\
WR6 & -0.203 & 284 & 0.839 & -0.762 & 236 & 0.447 & -0.510 & 147 & 0.611 \\
\hline
\end{tabular}

Missing information for all cognitive variables

\begin{tabular}{c|c|c|c|c|r|r|r|r|r}
\hline & \multicolumn{3}{|l|}{ Finnish children } & \multicolumn{4}{l|}{ German children } & \multicolumn{2}{l}{ Italian children } \\
\cline { 2 - 9 } & $\mathrm{t}$ & $\mathrm{df}$ & $\mathrm{p}$ & $\mathrm{t}$ & $\mathrm{df}$ & $\mathrm{p}$ & $\mathrm{t}$ & $\mathrm{df}$ & $\mathrm{p}$ \\
\hline WR2 & -0.860 & 274 & 0.390 & -0.871 & 245 & 0.385 & -1.537 & 147 & 0.126 \\
WR6 & 0.354 & 284 & 0.723 & -0.039 & 237 & 0.969 & 1.197 & 147 & 0.233 \\
\hline
\end{tabular}


Table 3.

Descriptive statistics imputed from data for four phonological awareness tests, letter-sound connection, number recall tests, RAN tests, two-word reading tests, child's age at the beginning of first grade, child's language, and mother's occupation.

\begin{tabular}{|c|c|c|c|c|c|c|c|c|c|c|c|c|c|c|c|}
\hline & \multicolumn{5}{|c|}{ Finnish pupils $(\mathrm{n}=260)$} & \multicolumn{5}{|c|}{ German pupils $(n=224)$} & \multicolumn{5}{|c|}{ Italian pupils $(\mathrm{n}=149)$} \\
\hline & $\mathrm{n}$ & $\mathrm{M}$ & S.D. & Min & Max & $\mathrm{n}$ & $\mathrm{M}$ & S.D. & Min & Max & $\mathrm{n}$ & $\mathrm{M}$ & S.D. & Min & Max \\
\hline Initial Phoneme Identification & 260 & 9.43 & 1.06 & 1.00 & 10.00 & 224 & 8.54 & 1.95 & 0.00 & 10.00 & 149 & 9.28 & 1.65 & 1.00 & 10.00 \\
\hline Letter-Sound Connection & 260 & 18.99 & 4.52 & 0.00 & 22.00 & 224 & 12.96 & 6.34 & 1.00 & 26.00 & 149 & 18.77 & 6.02 & 1.00 & 26.00 \\
\hline Phoneme Blending & 260 & 7.69 & 2.25 & 0.00 & 10.00 & 224 & 6.92 & 2.34 & 0.00 & 10.00 & 149 & 8.28 & 2.14 & 0.00 & 10.00 \\
\hline Syllable Blending & 260 & 9.91 & 0.34 & 7.00 & 10.00 & 224 & 9.74 & 0.69 & 5.00 & 10.00 & 149 & 9.79 & 0.61 & 6.00 & 10.00 \\
\hline Syllable Segmentation & 260 & 8.27 & 2.20 & 0.00 & 10.00 & 224 & 5.68 & 2.36 & 0.00 & 8.00 & 149 & 4.58 & 2.38 & 0.00 & 8.00 \\
\hline STM Forwards & 260 & 6.40 & 1.34 & 3.00 & 12.00 & 224 & 7.19 & 1.55 & 3.00 & 13.00 & 149 & 6.54 & 1.42 & 4.00 & 11.00 \\
\hline STM Backwards & 260 & 5.52 & 1.22 & 2.00 & 9.00 & 224 & 5.51 & 1.41 & 0.00 & 10.00 & 149 & 5.38 & 1.24 & 0.00 & 8.00 \\
\hline RAN Letters (time) & 260 & 32.55 & 7.43 & 18.00 & 70.00 & 224 & 32.57 & 7.84 & 18.00 & 75.00 & 149 & 31.94 & 7.36 & 20.00 & 72.00 \\
\hline RAN Pictures (time) & 260 & 55.25 & 9.97 & 34.00 & 102.00 & 224 & 58.99 & 14.14 & 35.00 & 117.00 & 149 & 55.84 & 10.40 & 34.00 & 95.00 \\
\hline WR1 & 260 & 42.92 & 19.43 & 0.00 & 80.00 & 224 & 9.53 & 7.18 & 0.00 & 34.00 & 149 & 11.16 & 6.00 & 0.00 & 28.00 \\
\hline WR2 & 260 & 70.98 & 11.80 & 35.00 & 80.00 & 224 & 31.78 & 9.73 & 5.00 & 59.00 & 149 & 31.01 & 10.58 & 6.00 & 60.00 \\
\hline $\begin{array}{l}\text { Child Age (at the beginning of } 1 \text { st } \\
\text { grade) }\end{array}$ & 260 & 7.11 & 0.25 & 6.60 & 7.81 & 224 & 6.66 & 0.39 & 5.68 & 7.90 & 149 & 6.17 & 0.30 & 5.44 & 7.23 \\
\hline Child's Language & 260 & .04 & .27 & 0.00 & 2.00 & 224 & .22 & .42 & 0.00 & 1.00 & 149 & .24 & .53 & 0.00 & 2.00 \\
\hline Mother's Occupation & 260 & 2.06 & 0.58 & 1.00 & 3.00 & 224 & 1.95 & 0.55 & 1.00 & 3.00 & 149 & 2.01 & 0.67 & 1.00 & 3.00 \\
\hline
\end{tabular}

Note. WR1 = Word Reading in $1^{\text {st }}$ Grade February, WR2 = Word Reading in $2^{\text {nd }}$ Grade May 
Table 4. Intercorrelations between phonological awareness tests (IPHI, PHB, SB, SS), LSC, STM (forward and backward), RAN (letters and pictures), WR1, WR2, and child's age. Finnish pupils $(n=324)$ represented in lower diagonal and German pupils $(n=283)$ in upper diagonal.

\begin{tabular}{|c|c|c|c|c|c|c|c|c|c|c|c|c|}
\hline & 1. & 2. & 3. & 4. & 5. & 6. & 7. & 8. & 9. & 10. & 11. & 12. \\
\hline 1. IPHI & & $.52^{* *}$ & $.45^{* *}$ & $.25^{* *}$ & $.18^{* * *}$ & $27^{* *}$ & $.20^{* *}$ & $-.14^{*}$ & $-.15^{*}$ & $.39^{* *}$ & $.34^{* *}$ & .05 \\
\hline 2. LSC & .07 & & $.55^{* *}$ & $.27^{* *}$ & $.15^{*}$ & $.22^{* *}$ & $.22^{* *}$ & -.10 & $-.24^{* *}$ & $.45^{* *}$ & $.36^{* *}$ & .09 \\
\hline 3. PHB & .02 & $.42^{* *}$ & & $.20^{* *}$ & -.03 & $.19^{* *}$ & .13 & -.06 & $-.16^{*}$ & $.38^{* * *}$ & $.30^{* *}$ & .10 \\
\hline 4. SB & -.02 & .08 & .03 & & $.20^{* * *}$ & .13 & .12 & -.01 & -.10 & .06 & $.15^{*}$ & .10 \\
\hline 5. SS & .01 & .10 & .02 & .00 & & $.14^{*}$ & .04 & -.03 & -.05 & -.02 & .02 & $.15^{*}$ \\
\hline 6. STM Forward & .014 & -.02 & -.03 & .00 & .03 & & $.26^{* *}$ & $-.13^{*}$ & -.05 & $.32^{* *}$ & $.27^{* *}$ & -.11 \\
\hline 7. STM Backward & .04 & .02 & .05 & .10 & -.03 & $.47^{* *}$ & & $-.17^{* *}$ & $-.21^{* *}$ & $.30^{* * *}$ & $.28^{* *}$ & -.05 \\
\hline 8. RAN Letters & -.05 & -.02 & -.09 & -.07 & -.02 & $-.19^{* *}$ & $-.18^{* *}$ & & $.40^{* *}$ & $-.32^{* *}$ & $-.47^{* *}$ & -.05 \\
\hline 9. RAN Pictures & -.01 & -.12 & $-.15^{*}$ & -.05 & -.10 & -.11 & $-.15^{*}$ & $.50^{* *}$ & & $-.30^{* *}$ & $-.37^{* *}$ & $-.18^{* *}$ \\
\hline 10. WR1 & .06 & $.47^{* *}$ & $.38^{* *}$ & .10 & .10 & .03 & .07 & -.02 & -.05 & & $.63^{* *}$ & .01 \\
\hline 11. WR2 & .05 & .03 & .11 & -.07 & -.05 & $.21^{* *}$ & $.24^{* *}$ & $-.33^{* *}$ & $-.18^{* *}$ & .12 & & .03 \\
\hline
\end{tabular}

** Correlation is significant at the 0.01 level (2-tailed). * Correlation is significant at the 0.05 level (2-tailed).

Note IPHI = Initial Phoneme Identification, LSC = Letter-Sound Connection, PHB = Phoneme Blending, SB = Syllable Blending, SS = Syllable Segmentation, STM = Short-Term Memory, RAN = Rapid Automatized Naming, WR1 = Word Reading in $1^{\text {st }}$ Grade February, WR2 $=$ Word Reading in $2^{\text {nd }}$ Grade May. 
Table 5. Intercorrelations between phonological awareness tests (IPHI, PHB, SB, SS), LSC, STM (forward and backward), RAN (letters and pictures), WR1, WR2, and child's age among Italian pupils $(\mathrm{n}=162)$.

\begin{tabular}{|c|c|c|c|c|c|c|c|c|c|c|c|c|}
\hline & 1. & 2. & 3. & 4. & 5. & 6. & 7. & 8. & 9. & 10. & 11. & 12. \\
\hline \multicolumn{13}{|l|}{ 1. IPHI } \\
\hline 2. LSC & $.34^{* *}$ & & & & & & & & & & & \\
\hline 3. PHB & $.49^{* *}$ & $.29^{* *}$ & & & & & & & & & & \\
\hline 4. SB & .14 & $.16^{*}$ & $.36^{* *}$ & & & & & & & & & \\
\hline 5. SS & .13 & $.17^{*}$ & .16 & .08 & & & & & & & & \\
\hline 6. STM Forward & .12 & .09 & $.29^{* *}$ & .03 & .13 & & & & & & & \\
\hline 7. STM Backward & $.28^{* *}$ & $.16^{*}$ & $.26^{* *}$ & .01 & $.33^{* *}$ & $.17^{*}$ & & & & & & \\
\hline 8. RAN Letters & -.07 & -.12 & $-.17^{* * *}$ & -.07 & -.02 & -.02 & -.11 & & & & & \\
\hline 9. RAN Pictures & -.05 & $-.25^{*}$ & -.09 & -.03 & -.13 & -.08 & -.11 & $.46^{* *}$ & & & & \\
\hline 10. WR1 & $.35^{* *}$ & $.45^{* *}$ & $.37^{* *}$ & .14 & $.17^{*}$ & $.17^{*}$ & $.46^{* *}$ & $-.36^{* *}$ & $-.36^{* *}$ & & & \\
\hline 11. WR2 & $.40^{* *}$ & $.45^{* *}$ & $.32^{* * *}$ & .05 & $.17^{*}$ & .14 & $.34^{* *}$ & $-.46^{* *}$ & $-.41^{* *}$ & $.69^{* *}$ & & \\
\hline 12. Child's Age & .04 & .14 & -.03 & -.004 & .06 & -.05 & -.02 & .06 & .05 & .04 & .01 & \\
\hline
\end{tabular}

** Correlation is significant at the 0.01 level (2-tailed). * Correlation is significant at the 0.05 level (2-tailed).

Note IPHI = Initial Phoneme Identification, LSC $=$ Letter-Sound Connection, $\mathrm{PHB}=$ Phoneme Blending, $\mathrm{SB}=$ Syllable Blending, SS $=$ Syllable Segmentation, STM $=$ Short-Term Memory, RAN $=$ Rapid Automatized Naming, WR $1=$ Word Reading in $1^{\text {st }}$ Grade February, WR2 $=$ Word Reading in $2^{\text {nd }}$ Grade May. 